\title{
Research on Spatial Components of The Qiang's Traditional Settlements under The Perspective of Spiritual Home
}

\author{
Xiaofei Wen ${ }^{1,2}$ \\ ${ }^{1}$ College of architecture, Southwest Jiaotong University, Chengdu, Sichuan, P.R. China. \\ ${ }^{2}$ College of urban planning and architecture, Southwest University for nationalities, Chengdu, \\ Sichuan, P.R. China
}

Email: 23976989@qq.com

\begin{abstract}
Keywords: Spiritual home, reconstruction, Qiang nationality, settles
Abstract. Historic changes have taken place in landscape of Qiang's settlements since Wenchuan Earthquake in 2008, which had effects on Qiang people's material life and spiritual life greatly. Studying landscape of Qiang's settlements based on spiritual homeland is an important way to examine whether the material environment construction is appropriate to national heritage and sustainable development. At first, The contents of the psychological cognitive level and the type of behavior activity of Qiang's traditional spiritual home are analyzed. Secondly, spatial components of the Qiang's traditional settlements and their relationships are sort out by field Research. Finally, the typical Qiang's reconstruction settlements in Aba are selected as the object of study, the manifestation of Qiang's spiritual home in the process of reconstruction is analyzed. Based on building material carrier, how to protect and inherit Qiang's spiritual home is taken into consideration.
\end{abstract}

\section{Introduction}

Qiang nationality is an ancient nationality with a large population in China, which played an important role in the history of China. And it is regarded as an important part of Chinese nation. According to the fifth national population census of China in 2001, the population of Qiang nationality is about 306,100 . More than $80 \%$ of them live in the upper reaches of Minjiang River area, which is located in the Southwest of China, mainly belonging to the administrative districts of Wenchuan, Maoxian, Songpan, Beichuan and so on. As we know, Wenchuan earthquake occurred in 2008, its epicenter was not a point but a line starting from YingXiu of Wenchuan County to Beichuan County, which almost covered the entire area of Qiang nationality. About 30,000 Qiang people were killed in the earthquake, accounting for $10 \%$ of the total population of Qiang nationality. Most of Qiang's settlements and their natural environments were damaged in different degree. Since the earthquake, Qiang's people have attracted much attention all over the world, Qiang's culture, architecture, folk customs, living environment have been analyzed by the academic researchers from the fields of anthropology, ethnology, sociology, architecture, ecology and other disciplines, with different perspective. To sum up, these studies can be broadly divided into two categories: one is the research on Qiang's material elements ,such as Qiang's architectue,the other is research on spiritual elements of Qiang's culture. Material elements and spiritual elements as the two main lines show the growth of Qiang's nationality, they have a strong correlation and affect each other. Spiritual home is the important support of Qiang's settlements Development and settlements are the material carrier of the Qiang's spiritual home. Therefore, studying the environments of Qiang's settlements based on spiritual homeland is a good way to examine whether the material environment construction is appropriate to national heritage and sustainable development.

\section{Related Theories and Research Methods}

Related Theories. The research on the relationship between landscape of Qiang's settlements and Qiang's spiritual home belongs to relationship research among people, environment and culture. The research mainly relies on environmental transactionalism in Environment-behavior studies. 
Based on Altman (1987) on the basis of mutual penetration of the summary: people and the environment is not independent of the two poles, but the definition and meaning of interdependence of an integral whole. The active function of human to the environment includes both material and functional role, and also contains the function of value and re interpretation. With the change of time, the whole system of man and environment has been changed.

\section{Research Methods.}

Literature Research. Through sorting out the related literatures on the Qiang's history, culture, and summarizes the meaning, content and form of Qiang's spiritual home.

Field Research. the typical Qiang's reconstruction settlements in Aba ,such as:Taoping village, are selected as the object of study. Using environmental psychology research methods, combined with the conclusion of literature research, through the field observation and interviews, find the corresponding relationship between the spiritual home and the traditional settlement landscape.

\section{The Meaning and Content Analysis of The Spiritual Home of Qiang Nationality}

The Meaning of Spiritual Home. The research on the relationship between landscape of Qiang's settlements and Qiang's spiritual home belongs to relationship research among people, environment and culture. Spiritual home refers to the common recognition, acceptance and relying on the spirit of value system of the community, which was produced by the constant integrations and absorptions in the historical process of the survival and development of the community.

From the constituent elements, the 'spiritual home' is an organic structure system, it is composed of different levels of the spiritual elements, which are connected with each other and interact with each other. Su Rongcai believed that spiritual home system includes both the low-level elements, such as: emotions, customs, traditions, and the high level of spiritual awareness including politics, law, morality, religion, art and philosophy.

The Content Analysis of Qiang Traditional Spiritual Home. Qiang is an old nationality. Since the beginning of the 20th century, Chinese and foreign scholars have carried out a series of research on Qiang nationality, gradually forming a comprehensive Qiang nationality research system. The research contents can be roughly divided into three aspects: the history of the ancient Qiang people, contemporary Qiang society and Qiang's culture.

Base on the summary of the existing research, from the perspective of environmental behavior, the compositions of Qiang's traditional spiritual home have two levels: one is the cognitive level of psychological, mainly including four aspects: national belief, social network, cultural identity and belonging sense; the other is activities level, such as: daily life, customs and festivals, production and construction activities.

Psychological Cognitive Level.

National belief. Qiang nationality worship nature, believing in "all things have spirit", is a multi God worship of the nationality. Belief is the core content of the national spiritual home.

Social networks. The traditional social network is mainly composed of kinship structure. A settlement usually consists of several surname of the family. For a long time, the social network has the characteristics of close, stable and inward.

Cultural identity. Cultural identity shows cognition of identity and uniqueness of Qiang's language, myths and legends, architectural culture, clothing culture and folk customs, etc.

A sense of belonging. That is the feeling of 'home' in a certain region of Qiang settlements, which includes strong sense of territory and security for the living environment of Qiang people.

\section{Behavioral Activity Level.}

Daily life. Worship and interaction are two important parts of Qiang's spiritual home in Qiang people's daily life. Because Qiang nationality are animist, believing gods are everywhere in life, daily worship became a part of daily life. For example, in Qiang people family ,different gods are placed in different places, also Qiang people worship different gods at a specific time. Layout of 
Most Qiang village is tight, the relationship between the family and the neighborhood is also very close, there are many communication spaces in the village.

Custom festival. Including marriage, funeral and other major festivals and folk activities. According to Qiang's tradition, weddings, funerals and other activities in a village are made by the villagers together with Qiang's unique ceremony. On the Qiang's new year's day and other important festivals, all the villagers participate in the all kinds of activities, such as dancing and sacrificing together, in activities the Shibi, who is an important monk in Qiang nationality, will sing with ancient Qiang language.

Production activity. Qiang people rely on agriculture for a living, land for farming is the Qiang people's most precious resources, has become the material basis of spiritual home.

Construction activities. Construction activities also can reflect the traditional spirit, which has four aspects: neighborhood help each other in construction, neighborhood share gable or roadway space, Shibi participates in the activities of the various ceremonies in construction, construction activities of defensive expression.

\section{Classifications of Qiang People's Traditional Settlement Spaces Base On Spiritual Home}

In the landscape of traditional Qiang's settlements, the behavior of spaces directly related to spiritual home ideology can be summarized as the following four types:

Belief Space. The belief spaces of the traditional settlements have basically formed different levels, such as: big space and small one, centralized space and decentralized one. There are three kinds of typical belief spaces. One is sacrificial place for all villagers or one family, such as sacred tree, temple space; the second are symbols or structures outside of buildings, such as white stone decoration, God worship; the third is the family god worship space inside the building.

Communication Space. Communication between human is an important way to form a stable social network. Communication space is everywhere in the traditional settlements, such as the village streets, house entrance, the roof to the house, fireplace, forming a different degree of private communication network, which can meet the communication needs of the villagers, neighborhood and family members. The villagers can communicate with different forms and depths in the process of daily life and labor.

Defense Space. The Qiang's traditional settlements usually put defense function in the first place, defense space is an important way to give of the sense of security and belonging for the villagers. Defense spaces embody in the Qiang's high watchtowers, the labyrinthic alleys, Water culvert through each house, the connected roof space, thick solid stone walls and other aspects.

Production of Space. Agricultural production is the material basis for the Qiang nationality. Therefore, arable land, water, climate and environment are important conditions for the location of the traditional settlements. Usually the location of settlement lies on hillside, where is suitable for crop growth, there muse be direct or indirect water source near the settlement and the cultivated lands surround settlements. Settlements, cultivated land and its surrounding natural environments constitute an organic habitat system.

\section{The Case Analysis of Spatial Components of The Qiang's Traditional Settlements}

Qiang nationality is one of the oldest nationalities in China, mainly living in upper reaches of Minjiang River in southwest of China. In the upper reaches of the Minjiang River, Minjiang River and its branches cut the edge of the Tibetan Plateau, causing many high mountains and deep valleys, which are called "valley" by local Qiang people, such as, Longxi valley, Puxi valley, Heihu valley and so on. Qiang's settlements are mainly are located on the high mountains and riversides of each valley. The environment of each valley usually has three remarkable characteristics. Firstly, their locations are remote, and usually on tough terrain, because it was very easy to make defense in ancient times. Secondly, there are farmland, forests, grassland and other production resources in each valley, so it is very easy for Qiang people to form many self-sufficient units by using those 
resources. Thirdly, there are many high mountains between valleys, so the transportation is difficult. It makes the villagers of each valley to be relatively independent groups, so it is easy to preserve the respective national characteristics. Taoping village is a typical Qiang's settlements, so we choose it as case study object.

Settlement Profile.Taoping village is located in the valley of Zagunao River which is a tributary of Minjiang River in Li County. It is 1440 meters above sea level. Because the valley wind influences crop growth, surrounding arable land is very limited. The old Taoping Village is located in one side of a main road along Zagunao River. The land is gentle slope topography more than 10 meters above the road.(Figure 1)

Belief Space.Qiang people worship nature, every family builds a tower-shaped structure(Figure 2) at the edge of the roof of his own house in order to worship the 'God', its orientation must be the same direction with the house gate. Shrine is set up inside of the house to worship the 'Family God', usually arranged on the wall opposite the gate. The iron triangle is placed near a fireplace as the symbol 'Fire God'. Belief space reflects the Qiang people's respecting for nature, it is an important connotation of Qiang's spiritual home.

Communication Space. Communication is important for Qiang people, neighborhood relationship of Qiang's settlements is close. Any outside place of the settlements can be a place of communication. When people encounter in the tunnel, when they do some sewing together, when they bask themselves on the roof, they always are happy to chat each other. The settlements with a sense of belonging can give the villagers a lot of pleasure, natural, random communication space. Inside the house, andiron is the most important communication space for a family. After dinner, family members sit around the andiron for warming themselves and communication.(Figure 3)

\section{Defense Space.}

Tower. Because of its location, security and defense are very important for the settlements. The towers, roadway and artificial water systems constitute a solid defense system for the settlements. The three towers are located in the center of the village, which have the function of lookout and guard. At the same time, because of their protruding height, it is very easy to supply spatial sense of hierarchy for the village, and also become the safeguard of spiritual home. (Figure 4)

Alleys. The village has many valleys, which have the features of small scale, shading, large height difference and complex layout. When the outcomers enter the valleys, they will be lost.

River System. Groundwater network system combined with the streets also has defense function. When it comes to an external invasion, every household cut off the water and enter the underground passage to escape.

Production Space. Due to the influence of wind, it is not conducive to the growth of crops, compared to the high levels villages, Taoping village has less arable land. According to the weather condition, villagers plant walnut, cherry and other fruit crops in the land surrounding the village. Cultivated land boundary also is the psychological boundary of villagers, settlements and arable land together constitute the Qiang people's life fields.

\section{Conclusions}

Under the theoretical framework of mutual penetration, the traditional Qiang's settlements and inheritance of spiritual home are complementary and interactive each other, they can form stable relations among human, environment and culture during the long-term development.

And in the process environment conversion after the earthquake, both cognitive psychology and behavior of Qiang's spiritual home have changed greatly, the total purpose of Qiang's settlement construction is to protect and inherit the Qiang's spiritual home, but many flaws have been found by field research. The big question that we should think is how to promote the constructions of Qiang's settlements in order to make it be the real carrier of sustainable development of Qiang's spiritual home and protection of Qiang's traditional culture. 


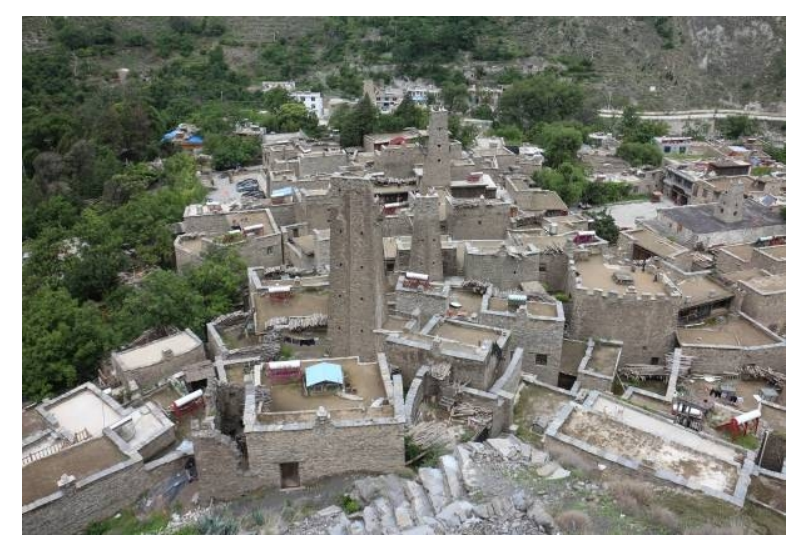

Figure 1 : Layout of Taoping Village

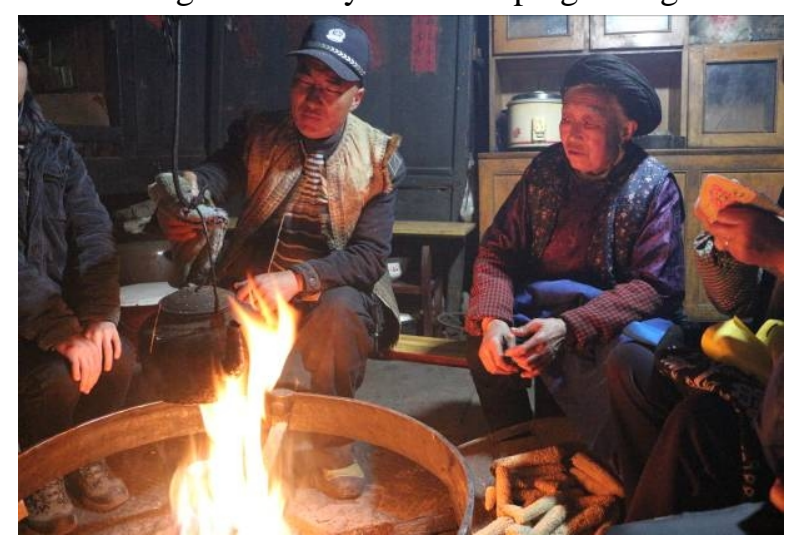

Figure 3 : Inside Communication Space

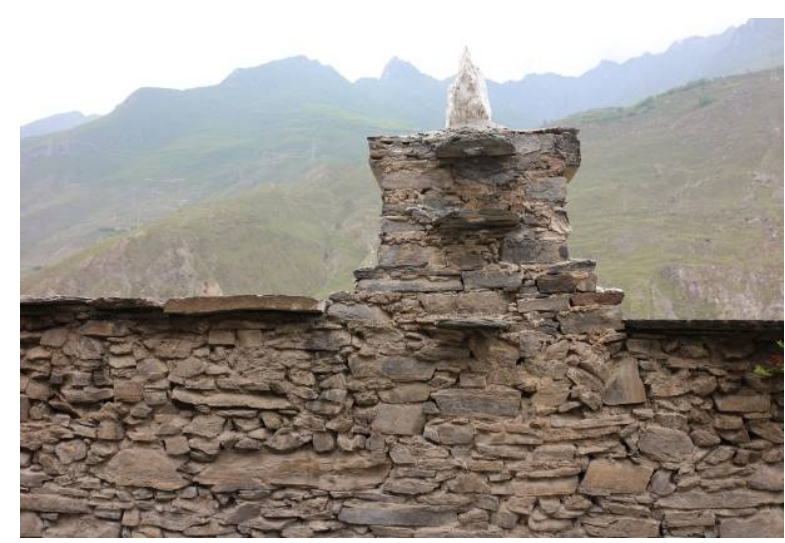

Figure 2 : Tower-Shaped Structure for Worship

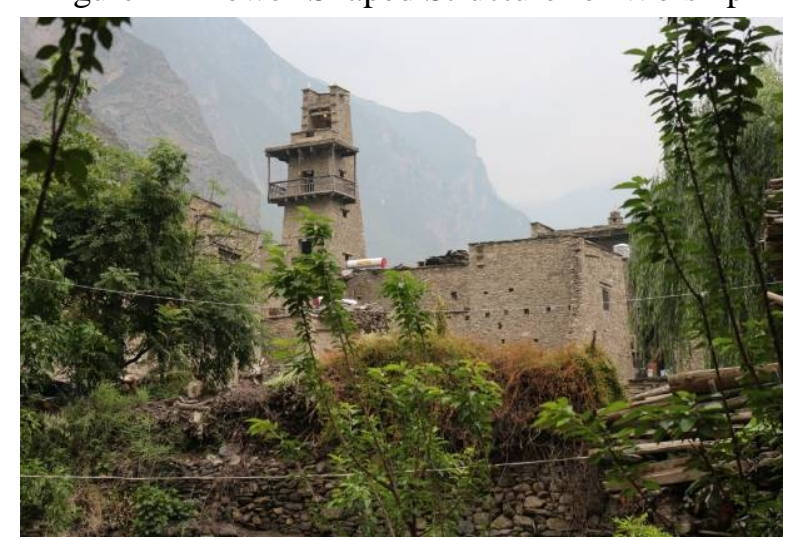

Figure 4 : Tower for Watch Out and Defense

\section{Acknowledgements}

This work was financially supported by the National Natural Science Foundation of China. Project Number: 51108394.Also was financially supported by science and technology support project funds of Sichuan Province. Project Number: 2013FZ0009.Also was financially supported by the Fundamental Research Funds for the Central Universities. Project Number:13NZYQN04.

\section{References}

[1] Mingying La. 'Research of the influence to Qiang' culture reconstruction by Qiang's villages rebuilt models and architecture types'. Forum on Chinese Culture,No.3:111-114, (2009) .

[2]Mingke wang. 'Between Tibetan and Han- the historical anthropology research of Qiang in Western Sichuan', Zhonghua Book Company, (2008)

[3]Xiaofei Wen. Chen Chen, Ying Meng. 'Reconstruction models of Qiang's settlements based on cultural inheritance', Journal of Southwest University for Nationalities.2012,.33(1):56-60

[4] Fuzheng Ji. Chinese season Qiang architecture [M]. Chengdu: Southwest Jiao Tong University press, 2000

[5] Ma Ning. Qiang intangible cultural heritage status and Protection Countermeasures -- Take Aba Tibetan and Qiang Autonomous Prefecture cases Journal of Guangxi University for Nationalities: Philosophy and Social Sciences Edition), 2007, 29 (3): 93-97 